\title{
3D LASER SCANNING OF RAILWAY LINE
}

$3 D$ laser scanning is very useful method to reach digital terrain model as the common output of map making. The paper deals with an application of $3 D$ laser scanning in railway track measurements, which belong to the field of engineering surveying. Experimental measurements were carried out on the ballast-less railway construction with the purpose to determine its track geometry by the combination of terrestrial and laser scanning methods. Measurements were carried out in conformity with conditions involved in corresponding technical standards. Surveyors used a variety of firmware, CAD and mathematical software for laser scanning processing to reach the expected outputs in adequate volume, accuracy and reliability.

Keywords: Laser scanning, terrestrial measurements, digital terrain model, ballast-less track construction.

\section{Introduction}

Laser scanning belongs to the non contact, fast and accurate methods, which bring highly detailed information about the observed object. It is a type of a surveying procedure with the wide application in the field of civil engineering, industry and architectural surveying, urban topography, reverse engineering, archaeology, mechanical dimensional inspection and many other fields of human activities. 3D laser scanning provides high quality surface modelling, 3D digitizing of mobile and portable objects, inspection and diagnostics in the process of reconstruction of various situations, product development, which means digital reproduction via $\mathrm{CAD}$ modelling of some assemblies and other procedures.

The article is focused just on the application of $3 \mathrm{D}$ laser scanning in engineering surveying. Up to now, surveyors have reached great experience with laser scanning by slope stability monitoring, bridge deformation measurement, mining and tunnelling, roadway and highway inspection to predict any deteriorations, plant and power station monitoring and observations of cities and historical buildings needed in the process of their reconstruction or documentation.

As classical photogrammetry, surveyors use both ground and aerial laser scanning (LIDAR). Its selection depends on how detailed and accurate data are required to be and what the range of monitored objects is.

The aim of the article is to describe the application of $3 \mathrm{D}$ laser scanning in the process of monitoring a railway track construction to find the optimal conditions and real measured accuracy that depends also on the instrument performance: accuracy, range and scan resolution. However, the selection of the optimal mathematical procedure reliable for surface modelling is also very important. Despite the fact that there has not been great experience with the scanning of the railway track construction, because of concern about possible surface reflexion of such a steel construction, the basic aim of this experiment was to reach the real track geometry resulted from the digital model obtained from a point cloud processing.

\section{Railway structure specification}

Railway modernisation in the Slovak Republic has brought reconstruction of the north route of railway line from west to east Slovakia with the aim to involve high-speed trains. The reconstruction is related to building the new unconventional type of railway structure, ballast-less track RHEDA 2000 [1], based on continuous reinforced concrete slab, which has been situated in the tunnel part of this railway route between towns Trencin and Nove Mesto n/Vahom. For this fact, the experimental measurements of the representative parts of such a railway

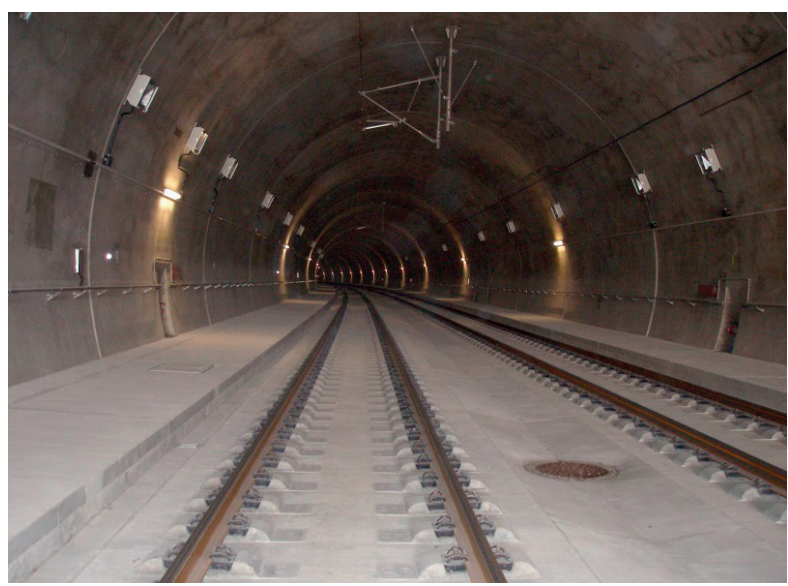

Fig. 1 Ballast-less track structure in the tunnel

\footnotetext{
* Jana Izvoltova ${ }^{1}$, Peter Pisca ${ }^{1}$, Vladimir Kotka ${ }^{1}$, Marian Mancovic ${ }^{2}$

${ }^{1}$ Department of Geodesy, Faculty of Civil Engineering, University of Zilina, Slovakia

${ }^{2}$ The Institute of Foreign Languages, University of Zilina, Slovakia,

E-mail: jana.izvoltova@fstav.uniza.sk
} 
construction were carried out. The experimental location is situated in the railway tunnel (Fig. 1), railway bridge (Fig. 2) and transient sections between the ballast-less track and traditional track structure (Fig. 3) to verify the possible track geometry changes caused by traffic loading.

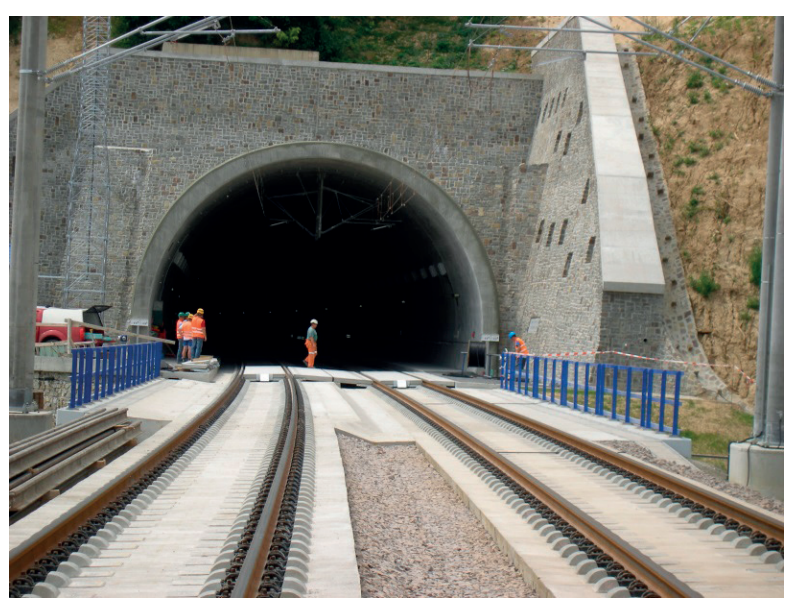

Fig. 2 Ballast-less track above the railway bridge

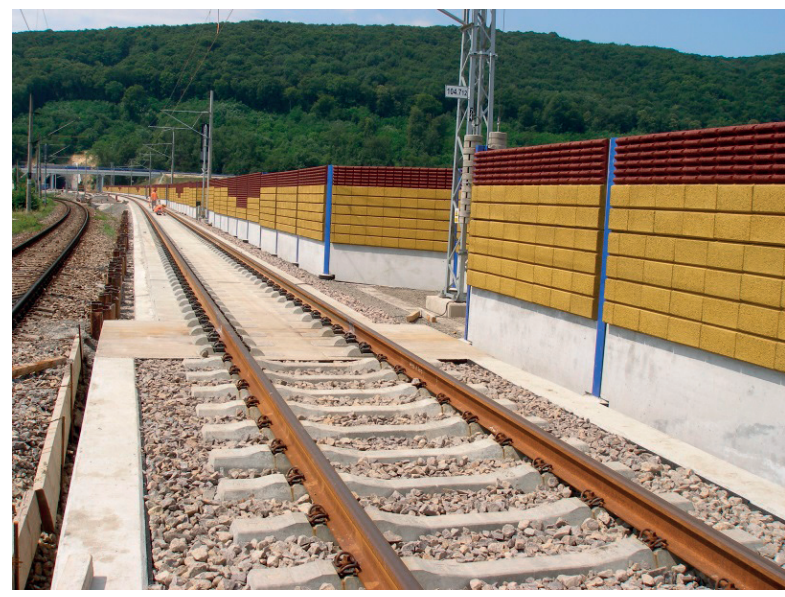

Fig. 3 Transient part between ballast-less track and traditional foundation

Railway needs a regular maintenance to keep its deformation and straining, caused by traffic, within elastic limits, otherwise the permanent deformations occur which bring track geometry changes and, consequently, increase the traffic loading efficiency. Now, the track inspection and maintenance is done in the competence of Slovak Railways and it is facilitated by a variety of specialised railway machines. Common maintenance jobs include surfacing and lining track to keep straight lines gauge and curves within maintenance limits [2].

For the purpose to define the track in the absolute position within the national positional reference system, additional geodetic measurements are required. Besides the precise digital levels, which bring absolute heights of railroad, also total stations,
GNSS systems or 3D laser scanners can be used to determine absolute three dimensional position of the track layout.

\section{Technical requirements for measurements}

Generally, the process of control measurements of building objects is carried out in conformity with the complex of technical standards STN 730202 - 73 0280, which define the general requirements, purpose, conditions, accuracy and tolerances needed for their measurement and evaluation. Notably, Technical Standard STN 730275 [3] is oriented to the accuracy control of three dimensional geometry of the line building objects including their horizontal and vertical layout, longitudinal elevation, transverse elevation and control of the mutual distances between line objects in crossroads. In Slovakia, the Direction SR 103-8 [4] designates special conditions for measurement of the ballastless high speed track, built from continuous reinforced concrete slab, which links to the direction SZDC S9 [5] valid in the Czech Republic.

Technical standard [3] defines accuracy of the control measurements of building objects by the value of standard deviation:

$$
\sigma_{\text {meth. }}=0.5 \delta_{\text {meth. }}
$$

where maximal value of control measurements $\delta_{\text {meth }}$ depends on a prescribed tolerance value $\Delta x$ of a particular measured parameter of track (f. e. track gauge, elevation, curvature, etc.):

$$
\delta_{\text {meth. }}=0.2 \Delta x
$$

\section{3D laser scanning of railway track}

Recently, 3D laser scanning has become a very useful method for acquiring the accurate three-dimensional detail of a complex observed object or facility, but its application in engineering surveying has some limitations resulting from the uniqueness of the measured structure. Railway track belongs to the long line ground objects and so the technology of its laser scanning has to be conformed to this fact.

For the scanning procedure of rail track, we used a pulsed dual-axis compensated laser scanner Leica ScanStation C10 with the prescribed accuracy of single measurement in position $\pm 6 \mathrm{~mm}$ and in distance $\pm 4 \mathrm{~mm}$ and angular accuracy is \pm 12 ". These specifications designate standard deviation for target acquisition $2 \mathrm{~mm}$. The scanning system is based on $3 \mathrm{R}$ green laser of wavelength $532 \mathrm{~nm}$ with the scanning range 300 meters [6].

Scanner stations were situated on both sides of the railway lines and their 3D position was determined by the resection method in dependence of the railway benchmarks position. A point cloud was gathered in scan resolution $3 \mathrm{~cm}$ at a range of 30 meters while keeping the prescribed accuracy in position $\pm 6 \mathrm{~mm}$. The scan area was limited by the horizontal field of view from $0^{\circ}$ to $180^{\circ}$ and vertical field of view from $-45^{\circ}$ to $+90^{\circ}$. 


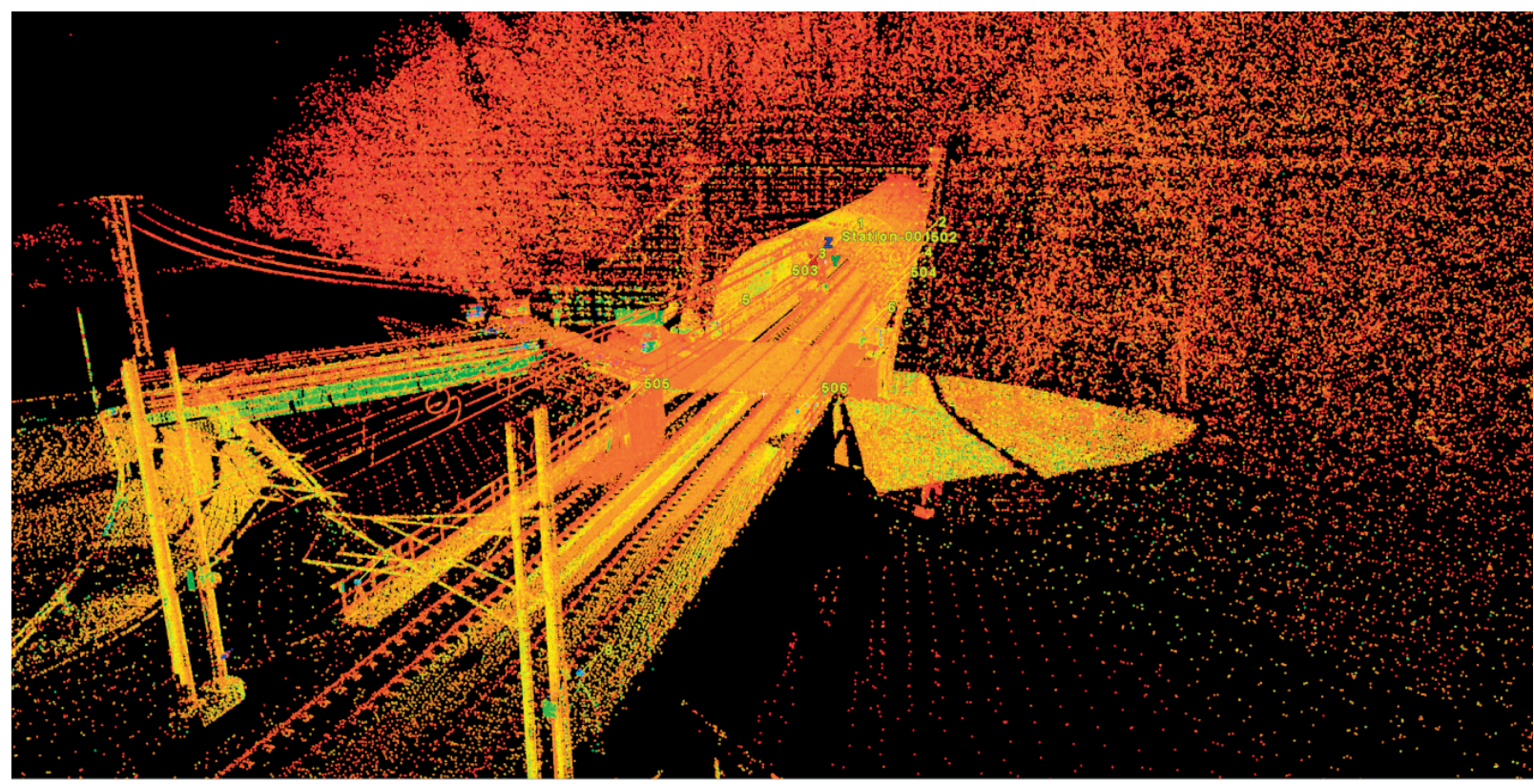

Fig 4 Point cloud of the northern part of the tunnel

Specifically, the experimental location is situated at the railway section $102.360-102.535 \mathrm{~km}$ in the southern part of the railway tunnel called Turecky vrch and at the section 104.200 $104.840 \mathrm{~km}$ in the northern part of the tunnel built in the railway route Bratislava - Zilina. The scanning process produces about 9 million points organized in a point cloud, each with their own unique $\mathrm{x}, \mathrm{y}, \mathrm{z}$, which occupies about 277 MBytes of a computer memory.

\section{Point cloud processing}

The great volume of raw data gathered by laser scanning, so called point cloud, is utilized by the Cyclone firmware of Leica Geosystems (see Fig. 4) and by CAD software. The point cloud processing belongs to the most time-consuming and a very important part of data utilization.

Each point in the point cloud is measured with the respect to the scanner position, and so the parameter transformation from a local to global national system is necessary to fit the point cloud to the global coordinate system. For this fact, the connection between laser scanning and terrestrial measurement is necessary, which is based on the 3D position of identical points of the both systems. The combination of the both measurement methods also helps to verify the positional data, which are utilized in the post processing procedures [7]. The positional control of observed point cloud is also realized by the photogrammetric method which enables the overlapping of digital photos made by video camera, with corresponding scans [8].

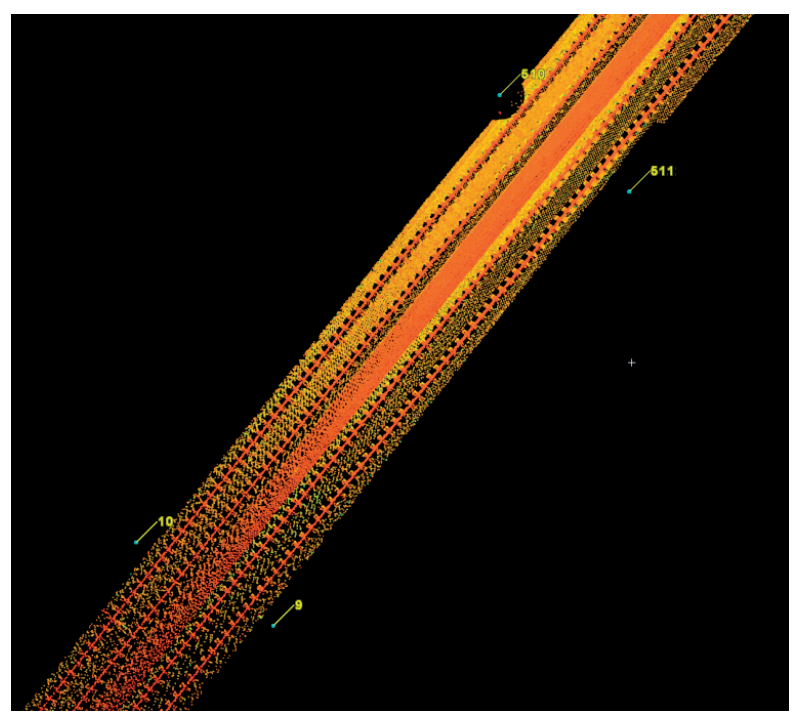

Fig. 5 Point cloud with noise removing in cyclone

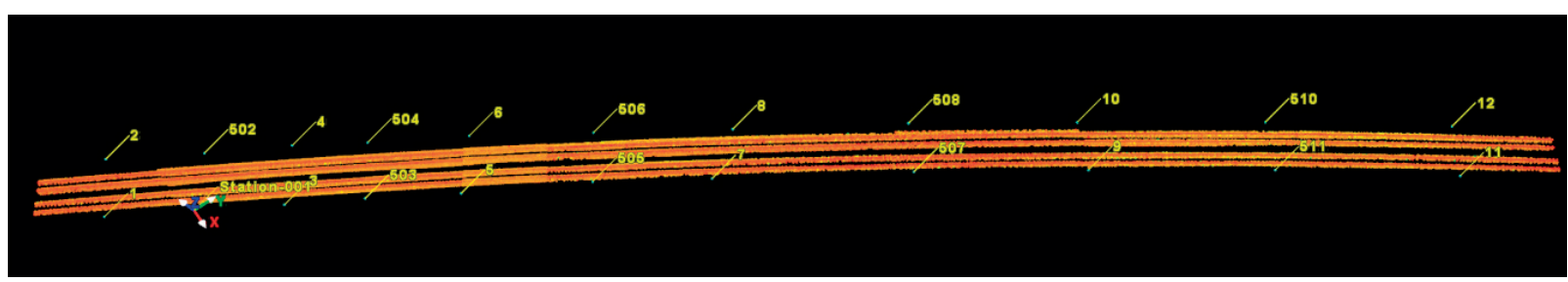

Fig. 6 Railway with two rail tracks in cyclone 


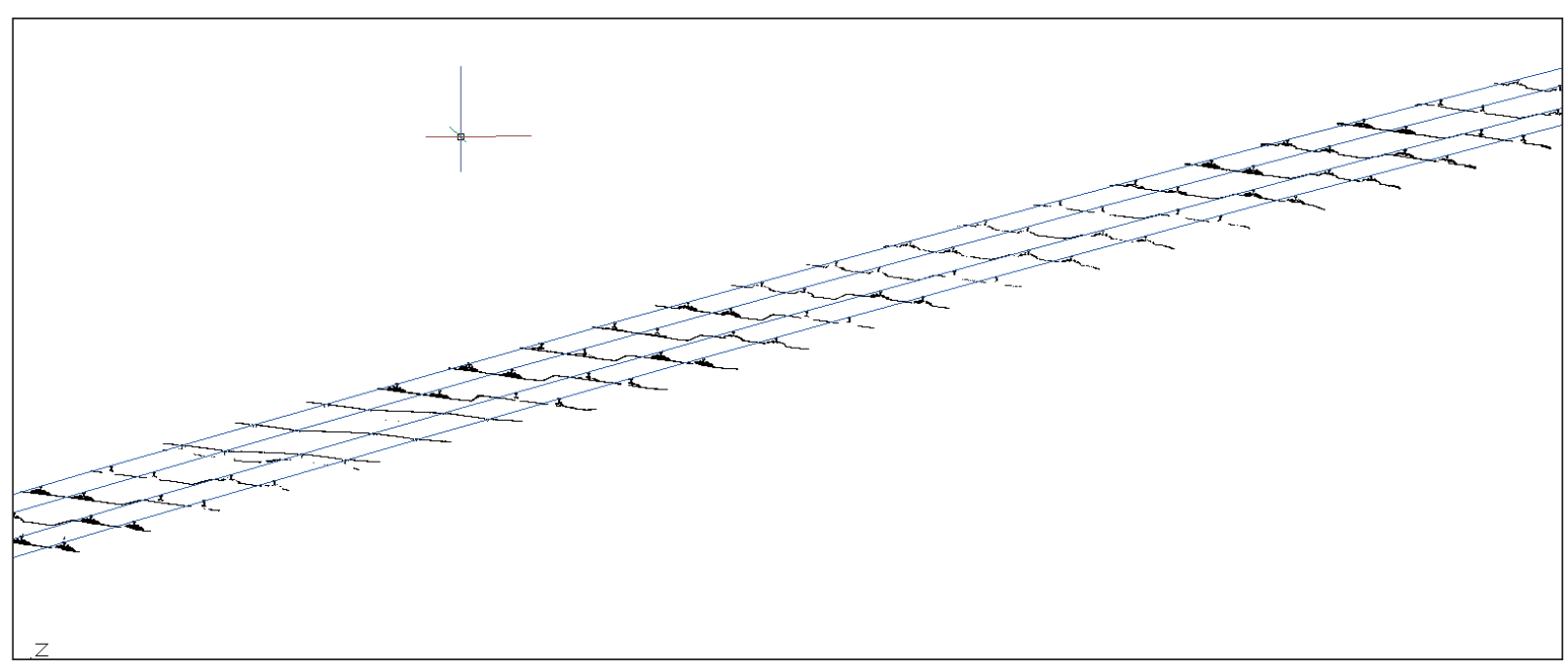

Fig.7 Railway tracks in AutoCAD

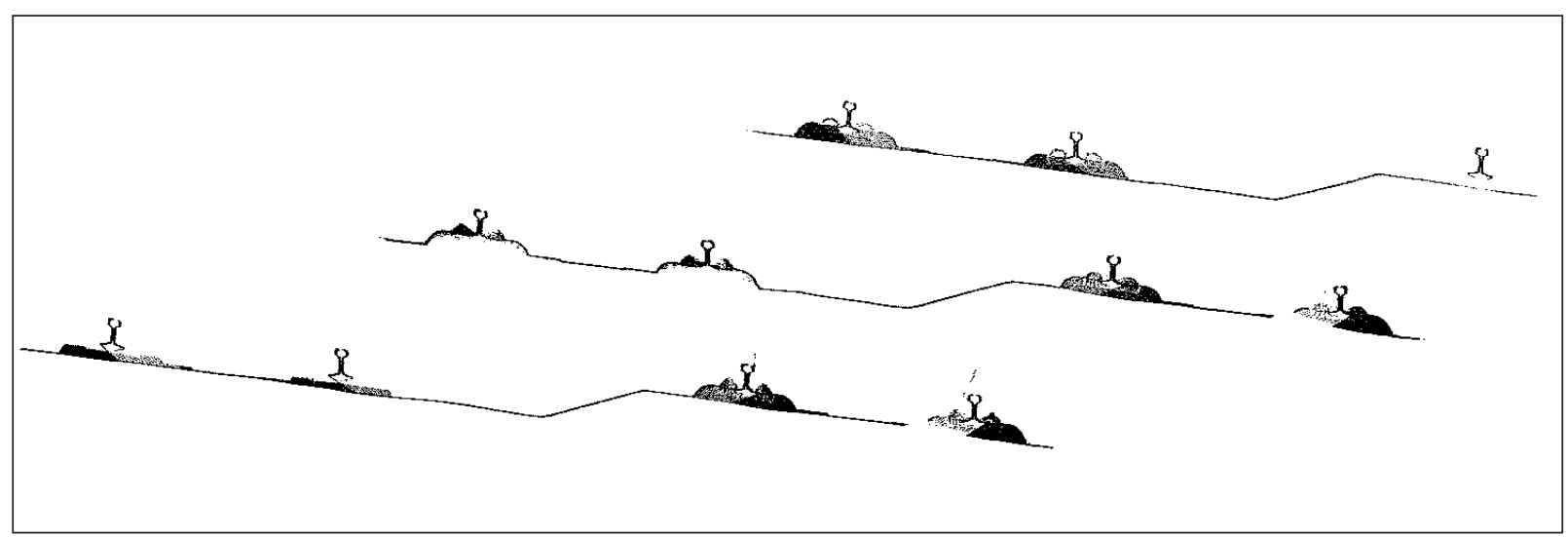

Fig. 8 The scan detail of track shape UIC60

The point cloud processing continues with the feature codes extraction directly from the point cloud and their export to feature code processing software. While scanning a site, the scanner captures everything in the selected field of view. Objects which are not relevant to the surveyor have to be removed from the scan. This removal process is an interactive process and a skilled operator needs only few minutes for extracting and deleting the useless objects. Figs. 5 and 6 show a successive objects extraction of scans which were processed by Cyclone software.

After process removing, the operator creates a digital terrain model, generates contours and measures among any points to calculate elevation differences, slope, axis position and the mutual distance between the railway tracks. This phase of laser scanning processing consists mostly of applying mathematical procedures especially to the regression analysis and mathematical modelling to receive the faithful model of reality [9]. The received mathematical model was finally used to reconstruct the railway track geometry (Figs. 7 and 8).

\section{Conclusion}

The application of the laser scanning brings to surveyors a great possibility to display the real world in many more details as it was in the past, and it also brings new approaches to utilization of scanning outputs by variety of software. For civil engineering, the most common output from laser scanning is the digital terrain model which can be applied in map making, designing, deformations diagnostics, construction inspection or reconstruction of the historical objects.

The article focuses on the description of the 3D laser scanning method in the process of railway track measurement to define railway layout in the national coordination system and, consequently, to determine the railway track geometry. The connection of terrestrial measurements and laser scanning is very important to define the point cloud in the global reference system, control 3D position of a point and, finally, assure accuracy and reliability of the whole digital terrain model. Measured accuracy depends especially on the used laser system and therefore, the 
surveyor has to conform the technology of measurement to its technical performance.

\section{Acknowledgement}

This article is the result of the implementation of the project: "Innovation and internationalization of education - the means to increase the quality of the University of Zilina in the European educational space (ITMS: 26110230079) supported by the Research \& Development Operational Programme funded by the ERDF.

\section{References}

[1] IZVOLT, L., HODAS, S.: Modernisation of Railway Infrastructure in the Slovak Republic. COMPRAIL XIII. Intern. Conference on Design and Operation in Railway Engineering. WIT Press Southampton, Boston, ISBN 978-1-84564-616-5

[2] VILliM, A., MUZIK, J.: Railway Line Route Trstena - Nowy Targ, the Possibilities of Maintenance. 15. Science Conference of PhD. study, VUT Faculty of Civil Engineering, Brno, 2013, ISBN 978-80-214-4669-4.

[3] STN 730275 Control Measurements of Line Building Objects. Slovak Technical Standard, Bratislava 1985

[4] Direction SR 103-8 (S) General Demands on Designing, Building, Maintenance and Work Acceptance on Ballast-less Structure of Railway Line. Direction of Slovak Railways, Bratislava

[5] Direction SZDC S9 Continuous Railroad, Railroad Administration, Czech Republic, Prague, 2012

[6] HDS Training Manual. Leica Geosystems HDS LLC European Office. Geotech Bratislava

[7] SIMA, J., SEIDLOVA, A.: Utilization Reflector-loss Distance Meter Leica for Measurement of Rock Walls. XXI Russian-SlovakPolish seminar, Moscow: Archangelsk, 2012 ISBN 978-83-7814-021-4

[8] COINER, CH., BRUN, A. P.: 3D Laser Scanning for Common Surveying Applications Cyra technologies, Inc. A Leica Geosystems Company: San Ramon, CA, 2006

[9] MUZIK, J., KOVARIK, K., SITANYOVA, D.: Meshless Analysis of an Embankment Using Local Galerkin Radial Point Interpolation Method (LGRPIM), Communications - Scientific Letters of the University of Zilina, No. 2, 2013, ISSN 1335-4205, p. $34-40$. 